\section{(6) OPEN ACCESS}

\title{
Rheumatic heart disease across the Western Pacific: not just a Pacific Island problem
}

\author{
Marian Abouzeid, ${ }^{1}$ Judith Katzenellenbogen, ${ }^{1,2}$ Rosemary Wyber, ${ }^{1}$ David Watkins, ${ }^{3,4}$ \\ Timothy David Johnson, ${ }^{1}$ Jonathan Carapetis ${ }^{1,5}$
}

\begin{abstract}
- Additional material is published online only. To view please visit the journal online (http://dx.doi.org/10.1136/ heartasia-2017-010948).

${ }^{1}$ Telethon Kids Institute, University of Western Australia, Subiaco, Australia ${ }^{2}$ School of Population and Global Health, University of Western Australia, Subiaco, Australia

${ }^{3}$ Department of Medicine, University of Cape Town, Cape Town, South Africa ${ }^{4}$ Department of Medicine, University of Washington, Seattle, United States

${ }^{5}$ Princess Margaret Hospital for Children, Perth, Western Australia
\end{abstract}

Correspondence to Prof Jonathan Carapetis, Telethon Kids Institute, 100 Roberts Rd, Subiaco 6008, Western Australia; jonathan. carapetis@telethonkids.org.au

Received 11 July 2017 Revised 9 August 2017 Accepted 11 August 2017

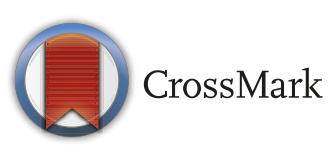

To cite: Abouzeid M, Katzenellenbogen J, Wyber R, et al. Heart Asia 2017:9:1-14. doi:10.1136/ heartasia-2017-010948

\section{ABSTRACT}

Some of the highest recorded rheumatic heart disease (RHD) prevalence and mortality rates are from the World Health Organization's Western Pacific Region (WPR). RHD burden has been well documented in much of the WPR subregion of Oceania, but less is known about RHD outside the Pacific Islands and Australasia. We aimed to review RHD burden in WPR outside Oceania to identify countries with high RHD burden and those with contemporary data gaps. We searched the peer-reviewed literature for English-language primary studies published between 1980 and April 2017 that reported RHD prevalence or mortality in the 13 WPR countries/areas outside Oceania, and Taiwan. We also searched for official government reports and health indicator documents. Results were synthesised narratively and reported stratified by 2015 Human Development Index (HDI) level. 30 peer-reviewed publications fulfilling inclusion criteria were identified, representing nine countries/areas. RHD prevalence and mortality have fallen in association with economic development, particularly in very high HDI countries. In several countries that have undergone recent economic development, RHD persists particularly among older populations. In poorer WPR countries there is a persistent RHD burden, including in young populations. Some countries had no available data. Although RHD burden has declined in many high-resource settings across the WPR, in several poorer countries, the impact of RHD appears to continue. Elsewhere, insufficient contemporary data make it difficult to gauge the current status of RHD burden and control. Concerted efforts are needed to fill information gaps and implement action to address this avoidable disease.

Rheumatic heart disease (RHD), an avoidable consequence of acute rheumatic fever (ARF), disproportionately affects the world's most vulnerable people. It is estimated that there are approximately 33 million people living with RHD. ${ }^{1}$ In high-income countries, the burden of RHD decreased markedly during the 20th century, attributable to improved living conditions associated with socioeconomic development and advances in medical management. However, RHD continues to exact a considerable toll in many low-resource settings. The epidemiology of RHD largely parallels most indicators of poverty; there are profound disparities in disease burden globally, with prevalence increasing with increasing socioeconomic inequality. ${ }^{2}$

Some of the highest recorded RHD prevalence and mortality rates are from countries in the Western Pacific Region (WPR) of the World Health
Organization (WHO). The WPR comprises an estimated 1.8 billion people, across 37 countries and areas. ${ }^{3}$ These culturally and developmentally diverse nations also exhibit marked variation in the size and capacity of their health systems, healthcare expenditures and health information infrastructures. $^{45}$

RHD has been well documented in much of the WPR subregion of Oceania, which incorporates the 24 nations of the Pacific Islands and Australasia. Less is known about RHD in WPR nations outside Oceania. It is plausible that there are impoverished geographical areas where high RHD burden persists. Without sufficient data to inform a policy and programmatic response, RHD may be undetected, unreported and unmanaged at both the individual and population levels.

We aimed to review RHD burden in the WPR outside Oceania to identify countries with high RHD burden and those with contemporary data gaps.

\section{METHODS}

We identified publicly available official health statistics and peer-reviewed literature documenting RHD prevalence or mortality in the WHO WPR Member State countries/areas outside Oceania, as well as Taiwan (figure 1). Oceania was considered out of scope as a similar project has already been conducted for that subregion. ${ }^{6}$

We searched the PubMed and Global Health databases during April-June 2017 with a search strategy incorporating a combination of 'rheumatic heart' OR 'rheumatic fever' terms and individual country names. The rheumatic fever string was included to ensure all relevant papers were captured. Additionally, we searched the Institute for Health Metrics and Evaluation's Global Health Data Exchange for RHD scientific literature, and relevant studies known to the authors were reviewed for eligibility.

Studies were eligible for inclusion if they were primary studies conducted in the non-Oceania Member States and areas of the WHO's WPR or in Taiwan; reported RHD prevalence or mortality rates or proportions for the general population or in specific population or clinical subgroups (obstetric, cardiovascular/echocardiograph populations, hospital admissions); were published between 1980 and April 2017 (regardless of study period); and full texts were available in English. We included studies that ascertained disease burden using any type of data source, including auscultation-based or echocardiography-based screening, administrative data or clinical records. Studies on RHD in 


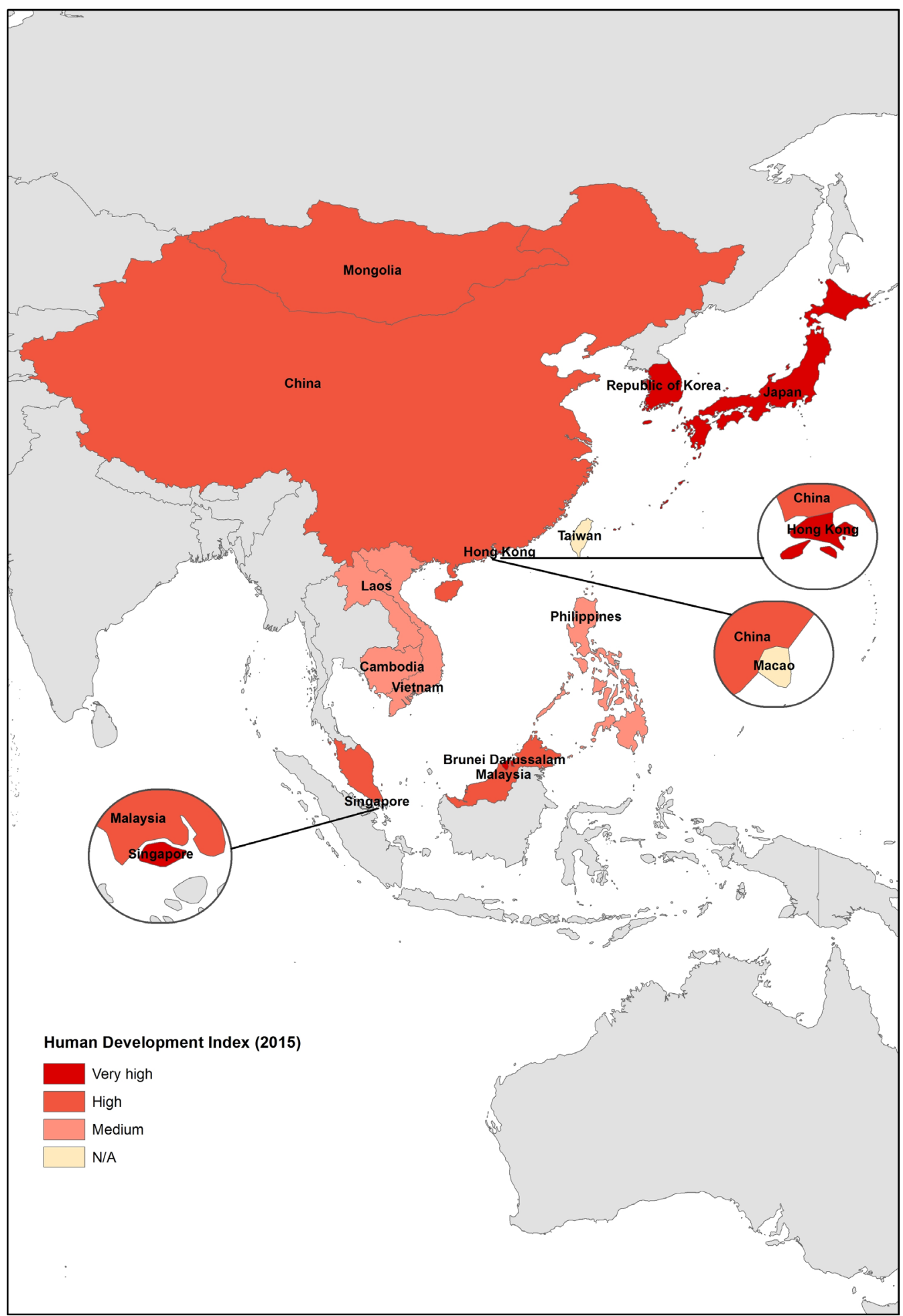

Figure 1 Countries and areas of the Western Pacific region included within the scope of this study. Taiwan does not have WHO Member State status but is within this geographical region and so was included in this study.

pregnancy were included only if the total number of pregnant women was reported, allowing calculation of the proportion with RHD. Studies focusing solely on ARF were excluded. Other specific exclusions are outlined in figure 2.

We also conducted a Google search for national statistical agency health indicator and vital statistics documents reporting RHD prevalence or mortality and published in English. Where available, summary statistics were extracted from the most recent reports.
Title and abstract screening and full text reviews were undertaken by two reviewers independently, with disagreements resolved by consensus; records retrieved via the expanded search strategy and grey literature were assessed by one reviewer. Relevant data regarding study methods and disease estimates were extracted and summarised by one reviewer, with discussion as required. In papers reporting multiple components, only those measures fulfilling inclusion criteria were included (eg, absolute numbers only with no rates were not extracted). Where multiple 


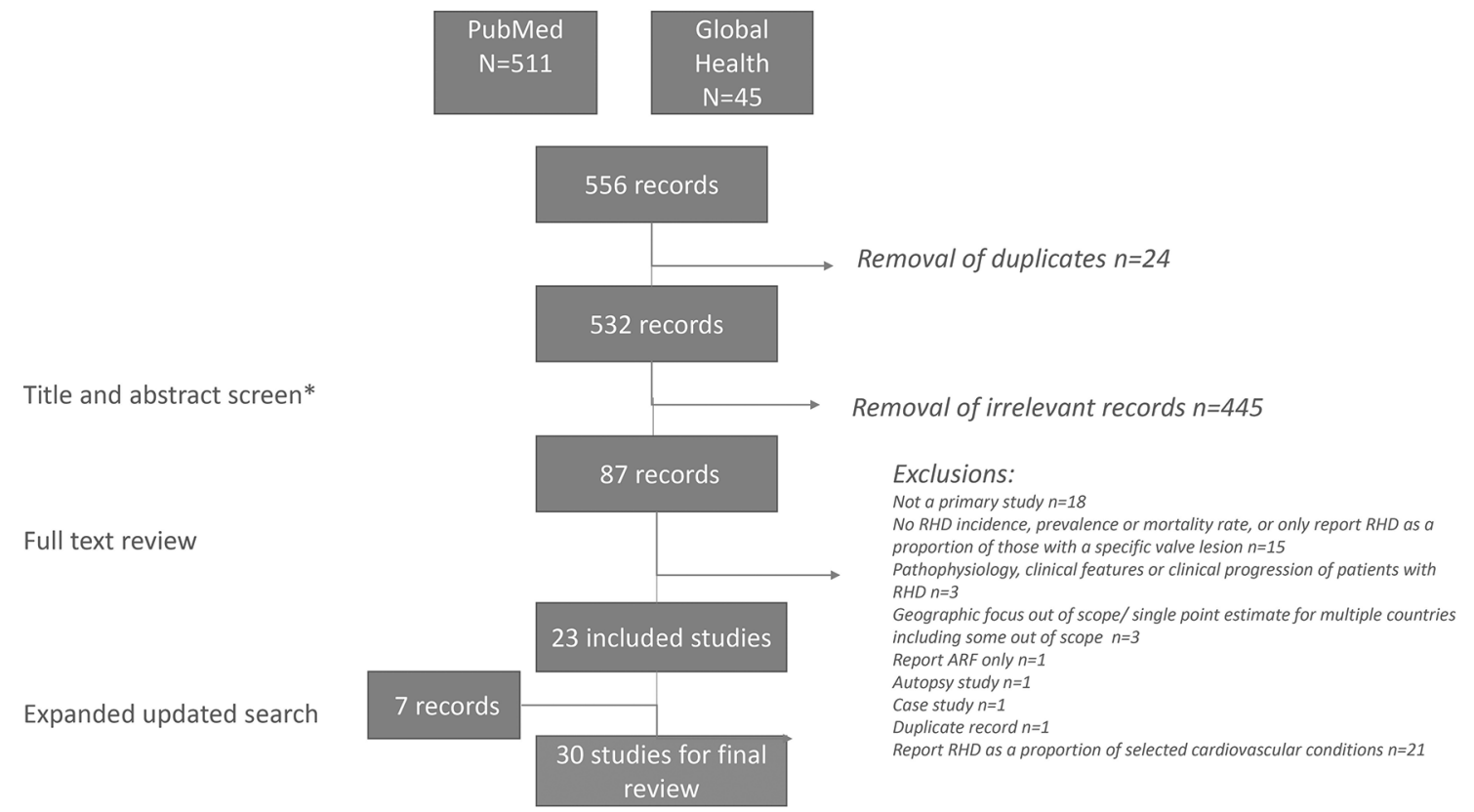

Figure 2 Summary of literature search results. *Exclusion criteria: not a primary study (including guidelines, conference proceedings, reviews); case studies; published in a language other than English; focus is pharyngitis burden/rates of group A streptococcal colonisation; focus is pathophysiology/ clinical features or clinical progression of patients with ARF/RHD; focus is outcomes or treatment effectiveness in patients with ARF/RHD; report proportion of patients with a specific valve lesion due to RHD but no population denominator; does not report RHD prevalence or mortality rates (including studies that only present absolute numbers); geographical focus out of scope or report single point estimate for multiple countries, including some out of scope. ARF, acute rheumatic fever; RHD, rheumatic heart disease.

estimates over a given period were presented, the earliest and the latest estimates were extracted and temporal trends noted.

Results are presented stratified by country level of development, with classification based on the United Nations Development Programme's Human Development Index (HDI) for 2015. ${ }^{5}$ The HDI is a composite measure that reflects life expectancy, average and expected educational attainment and gross national income per capita, with a higher score reflecting better performance on these measures. This scheme classifies countries as having very high (HDI scores $\geq 0.800)$, high (0.700-0.799), medium $(0.550-0.699)$ and low $(<0.550)$ human development. Studies from China were also mapped against province-level HDI. $^{7}$

Ethics approval was not required for the conduct of this study.

\section{RESULTS}

Of 37 countries and areas in the WHO's WPR, 11 countries and two Special Administrative Regions of China lie outside Oceania, as does Taiwan.

Figure 2 outlines the search strategy and handling of records. Full text review of 87 publications was undertaken, with 23 identified as relevant and a further 7 included following an updated search and review of papers known to the authors. ${ }^{8-37}$ Relevant RHD prevalence or mortality data were also retrieved from publicly available government documents for Brunei, ${ }^{38}$ Hong Kong, ${ }^{39}{ }^{40}$ Japan, $^{41}$ Mongolia $^{42}$ and the Philippines ${ }^{43}$; no official statistics were identified for other countries/areas.

Table 1 summarises the peer-reviewed paper characteristics, representing 9 of the 14 countries/areas. Of these, 12 papers reported population-based prevalence, 13 reported RHD as a proportion of total admissions/surgeries/echos performed or proportion of deliveries, and 9 reported mortality rates. Several papers used multiple data sources and report multiple metrics.
Study periods from Hong Kong, Singapore, Malaysia, the Philippines and Taiwan were all prior to 2000.

Tables 2-5 present burden estimates from countries with very high, high, medium and unspecified 2015 HDIs, respectively, and table 6 presents official statistics.

\section{RHD prevalence}

Very high HDI: Singapore, Hong Kong, Japan, South Korea, Brunei Two Korean papers covering 2006-2011 used administrative data to estimate prevalence, reporting high disease burden particularly among older age groups table $2 .^{910}$ Two other prevalence papers were early studies of younger populations that reported low RHD prevalence among university students in Hong Kong in the $1970 s^{12}$ and school children in Japan from the 1950 s to 1980 s. $^{14}$

Early reports of disease burden among hospital populations in these settings also indicate a low prevalence. In South Korea in the mid-1980s, RHD comprised approximately 5\% of adult cardiovascular admissions. ${ }^{8}$ In the 1960 s-1980s, RHD decreased as a proportion of cardiac admissions in $\operatorname{Japan}^{14}$ and RHD as a proportion of hospital and cardiac admissions was also low and declining in Hong Kong among both adult and paediatric patient populations. ${ }^{12} 13$ Recent Hong Kong government reports indicate 1736 of 79896 heart disease inpatient discharges or deaths in hospital in 2014 were due to RHD $^{39}$ (2.2\%).

Population-based or hospital-based prevalence estimates were not found for Brunei and Singapore, and the most recent data for Japan were from 1981 (prevalence in school children 0.14 per 1000). ${ }^{14}$

\section{High HDI: China, Malaysia, Mongolia}

Prevalence data were only available for China (table 3). Online supplementary figure S1 presents RHD data availability in China 
Table 1 Study details for peer-reviewed publications presenting estimates of RHD burden by country/area 2015 HDI status, 1980-2017

\begin{tabular}{|c|c|c|c|c|}
\hline & Very high HDI countries & High HDI countries & Medium HDI countries & HDI not specified \\
\hline Total number of papers & $\begin{array}{l}\text { All=11 } \\
\text { Brunei: } 0 \\
\text { Hong Kong: } 2 \\
\text { Japan: } 3 \\
\text { Singapore: } 2 \\
\text { South Korea: } 4\end{array}$ & $\begin{array}{l}\text { All=12 } \\
\text { China: } 11 \\
\text { Malaysia: } 1 \\
\text { Mongolia: } 0\end{array}$ & $\begin{array}{l}\text { All=4 } \\
\text { Cambodia: } 2 \\
\text { Laos: } 0 \\
\text { Philippines: } 2 \\
\text { Vietnam: } 0\end{array}$ & $\begin{array}{l}\text { All=3 } \\
\text { Taiwan: } 3 \\
\text { Macao: } 0\end{array}$ \\
\hline \multicolumn{5}{|l|}{ Coverage* } \\
\hline National & 6 & 0 & 1 & 2 \\
\hline Subnational & 3 & 5 & 2 & 2 \\
\hline Facility/facilities & 5 & 7 & 1 & 1 \\
\hline \multicolumn{5}{|l|}{ Study periodt } \\
\hline Prior to 2000 & 6 & 3 & 2 & 3 \\
\hline 2000 onwards & 2 & 6 & 2 & 0 \\
\hline Study period spans pre- 2000 and post- 2000 & 3 & 2 & 0 & 0 \\
\hline \multicolumn{5}{|l|}{ Metric } \\
\hline Prevalence: general population or population subgroup & 4 & 4 & 2 & 2 \\
\hline $\begin{array}{l}\text { RHD frequency among hospital/medical/cardiovascular/ } \\
\text { surgical/obstetric admissions }\end{array}$ & 4 & 5 & 1 & 1 \\
\hline RHD as a proportion of echos performed & 0 & 2 & 0 & 0 \\
\hline RHD mortality rates or proportions** & 5 & 1 & 1 & 2 \\
\hline \multicolumn{5}{|l|}{ Data source } \\
\hline Screening/clinical exam in other context & 2 & 4 & 2 & 2 \\
\hline Hospital admissions data or surgical database & 4 & 4 & 1 & 1 \\
\hline Health insurance data & 2 & 0 & 0 & 0 \\
\hline $\begin{array}{l}\text { Echocardiography database (including echo database for } \\
\text { inpatients) }\end{array}$ & 0 & 3 & 0 & 0 \\
\hline Mortality data & 5 & 1 & 1 & 2 \\
\hline
\end{tabular}

Numbers do not add to total number of papers as some reported multiple measures.

*Any study reporting on health facility populations denoted here as 'facility', regardless of whether the facility catchment area is national or subnational.

tFor one paper, study period not explicitly stated.

Note several papers, particularly among those published pre-1990, have inconsistent results reported throughout the text.

‡Some studies reported ARF and RHD in the same point estimate. ** does not include absolute counts only

ARF, acute rheumatic fever; HDI, Human Development Index; RHD, rheumatic heart disease.

by province and by province HDI score. Provinces for which data were available were generally those with higher development levels; several impoverished provinces had no data. Burden estimates varied subnationally, by population subgroup, data source and over time. For example, in Dongguan City, 5 of 81213 children aged 5-13 years screened in 2011-2012 had echo-confirmed RHD, ${ }^{21}$ equating to 0.06 per 1000 . Among adults aged 18-74 years from nine communities in urban and suburban China, prevalence of echo-detected RHD was 1.86 per 1000 in $2001-2002 .{ }^{20}$ In a study involving 13 provinces, 91 of 29079 subjects aged 30 and over, were reported to have $\operatorname{RHD}^{29}$ (3.13 per 1000). Earlier clinical screening data from Panyu County, Guangdong Province, demonstrated a prevalence of $2.5 \%$ in the general population aged over 15 years. ${ }^{19}$

The relative contribution of RHD to cardiovascular and general medical/paediatric admissions has generally decreased over time in China but still comprises a considerable caseload. For example, in Shanghai RHD accounted for $24.23 \%$ of all medical admissions with heart disease during 1980-1989, ${ }^{22}$ down to $2 \%$ of all cardiac admissions during $2000-2005 .{ }^{23}$ For one facility in Zhejiang over the period 2010-2015, RHD prevalence was $1.6 \%$ in adult patients. ${ }^{26}$ Similarly in 2008 RHD still comprised $20 \%$ of all cardiac surgery cases in Beijing. ${ }^{27}$ At a Shanghai facility, $0.5 \%$ of 20983 women delivering during 1993-2007 had RHD. ${ }^{28}$ RHD also comprised 3\% of all adult outpatient echocardiograms performed at a Shanghai facility in $2012^{25}$ and $33 \%$ of all valvular disease among inpatients at a Guangdong centre in 2013. ${ }^{24}$
Mongolian official government documents report 24116 new cases of ARF/RHD in 2012, and a total population of approximately 2.87 million, ${ }^{42}$ equating to 8.4 cases per 1000 . No Malaysian data were identified.

\section{Medium HDI: Vietnam, Philippines, Laos, Cambodia}

No population or hospital prevalence data were available for Vietnam or Laos (table 4).

Estimates of echocardiography-confirmed RHD prevalence among school children based on screening studies ranged from 1 per 1000 in Legazpi City, Philippines in $1998^{34}$ (screen by auscultation) to 21.5 per 1000 among children 6-17 years old in Cambodia in 2001-2002 ${ }^{31}$ (screen by echocardiography). RHD was the indication for $43 \%$ of all Cambodian cardiac surgery procedures between 2001 and 2006 and 29\% between 2007 and $2011 .^{32}$

\section{HDI unspecified: Taiwan, Macao}

No information was available specifically for Macao. Surveys (with examination in questionnaire-positives) in Taiwan show a significant decline in RHD prevalence in 1970-1985 from 1.4 to 0.62 per 1000 (table 5). ${ }^{36} \mathrm{ARF} / \mathrm{RHD}$ as a proportion of paediatric admissions fluctuated over the 1940s-1980s, to approximately 15 per 1000 admissions in $1981 .{ }^{37}$

\section{RHD mortality}

Mortality data in peer-reviewed literature were only available for six countries/areas. 


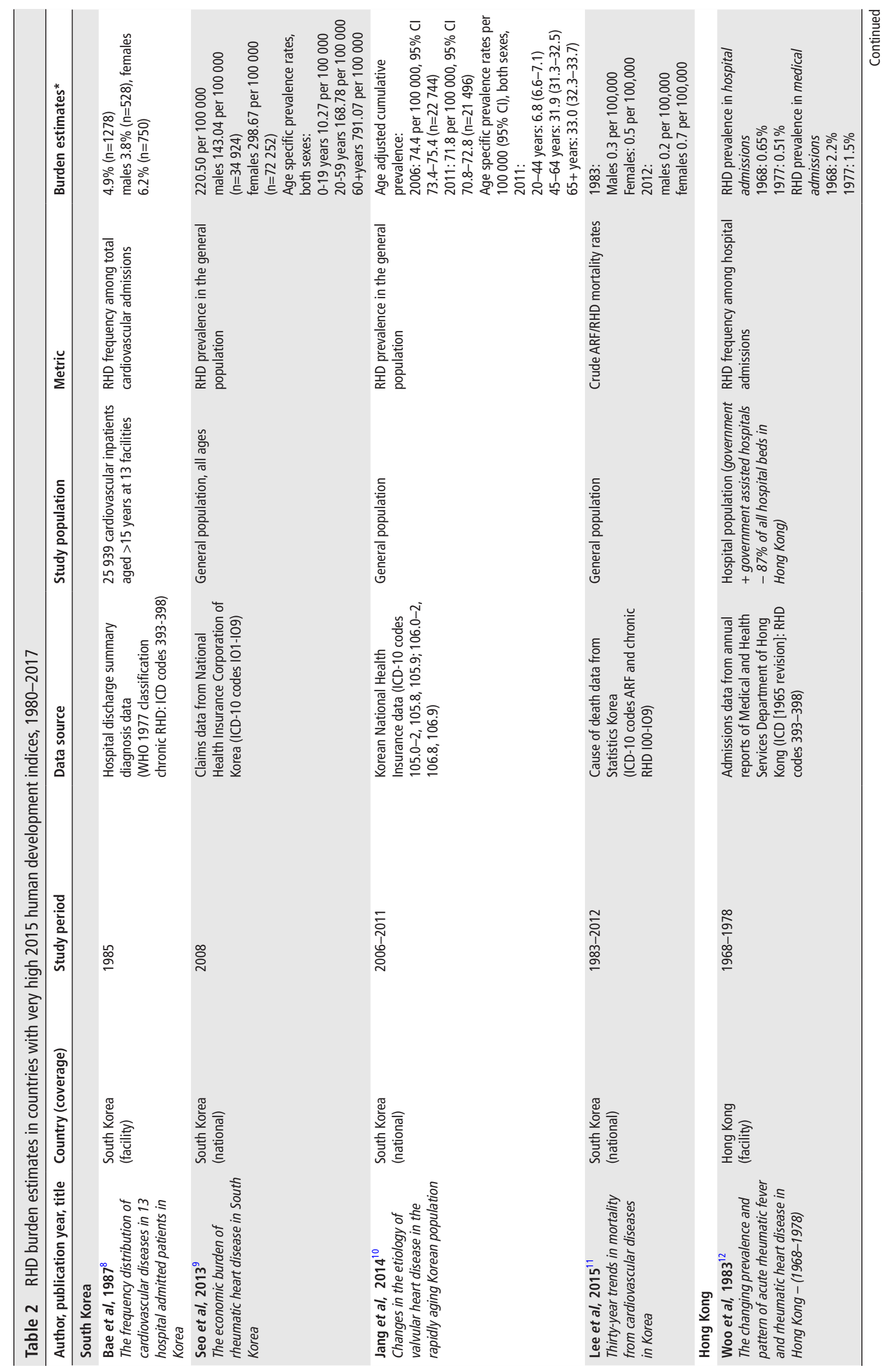

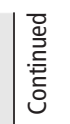




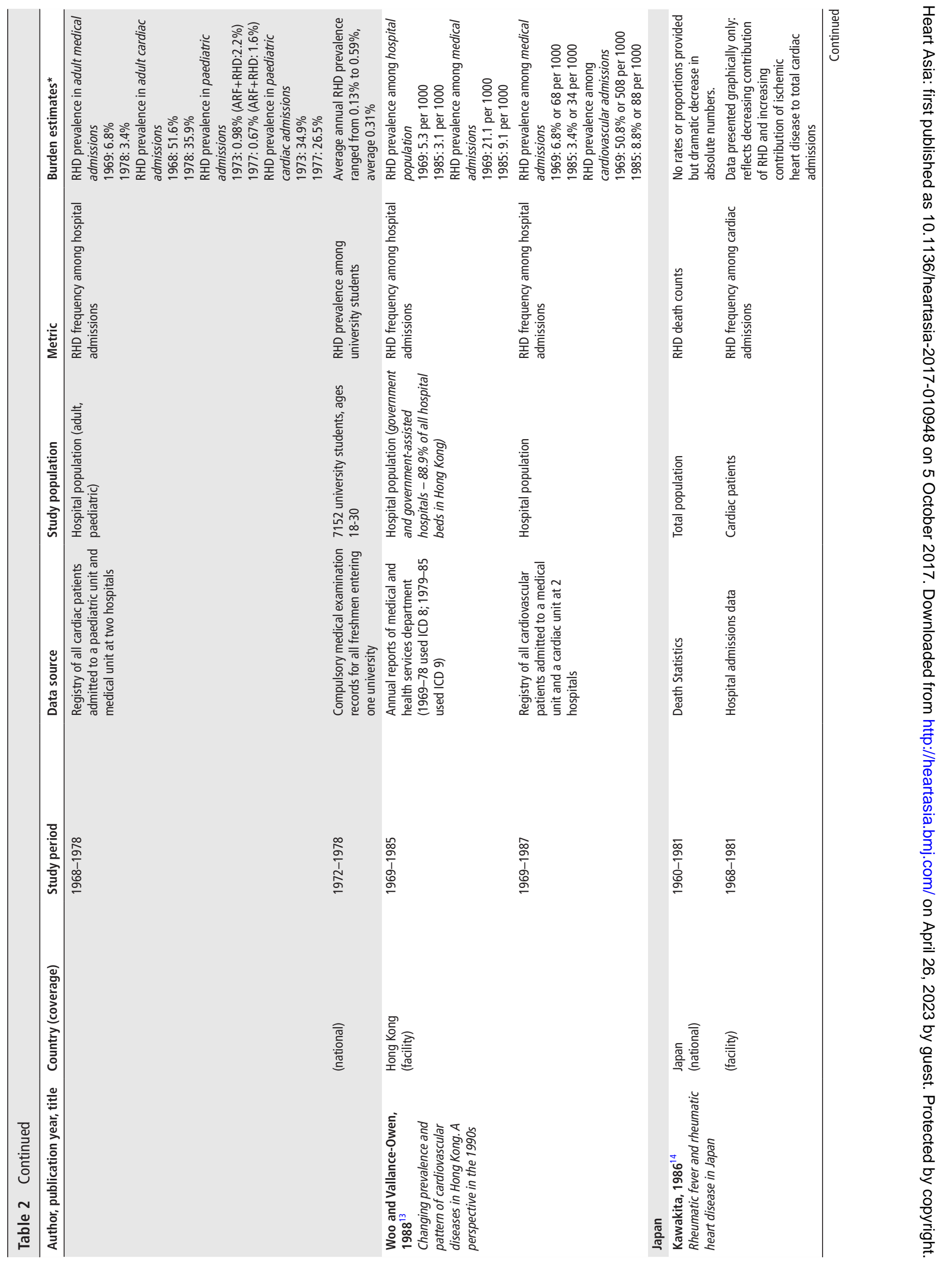




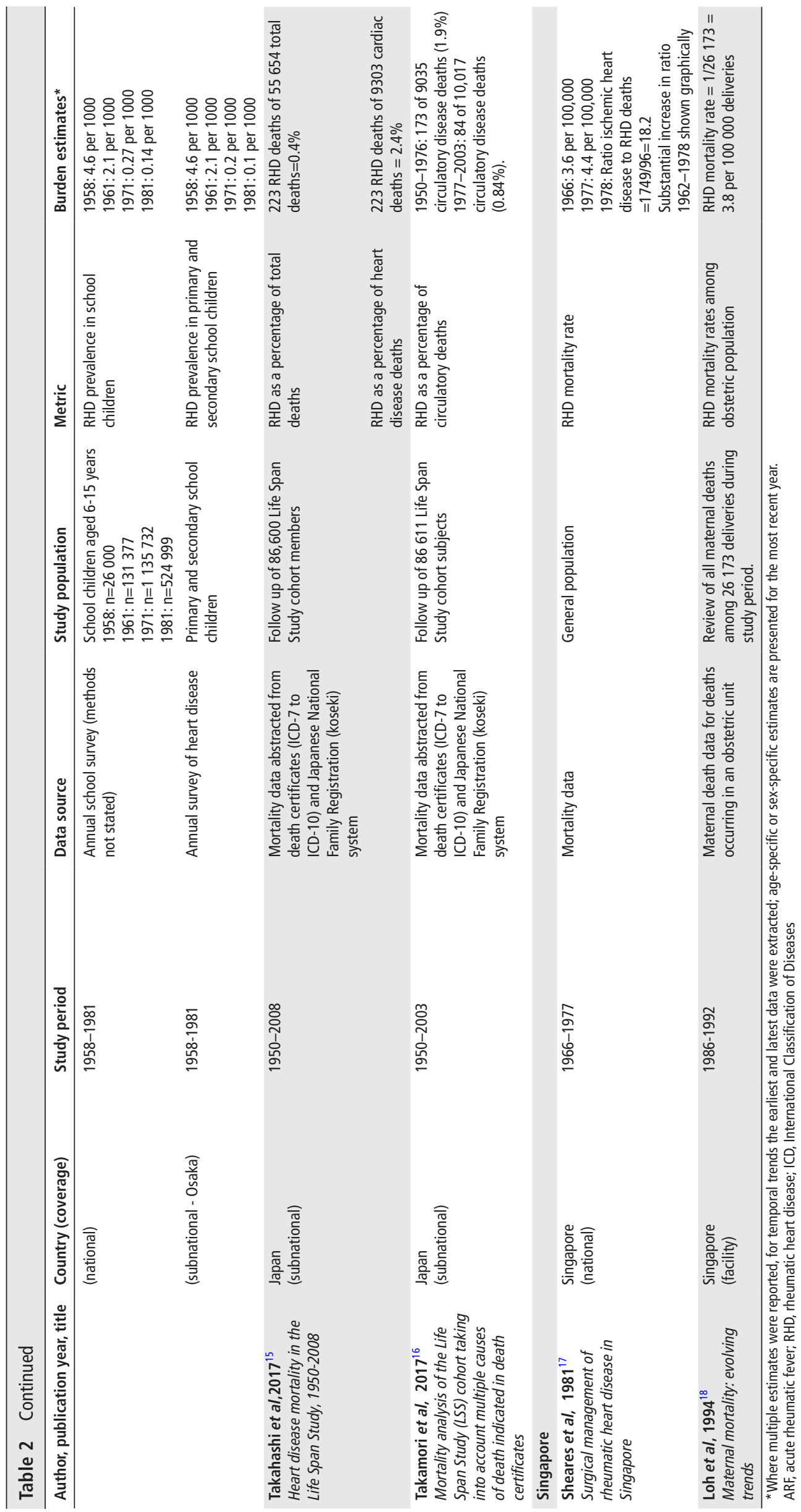




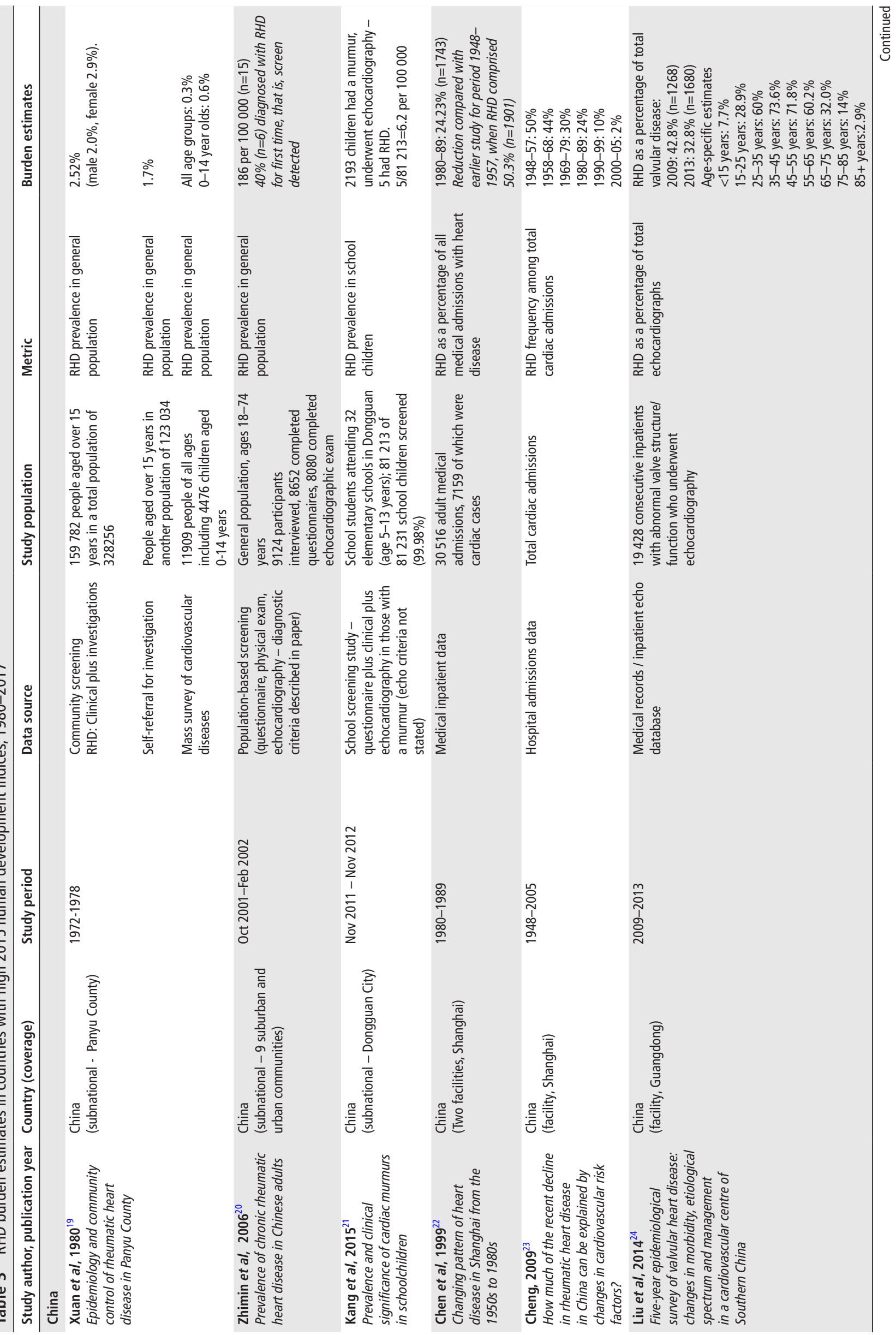




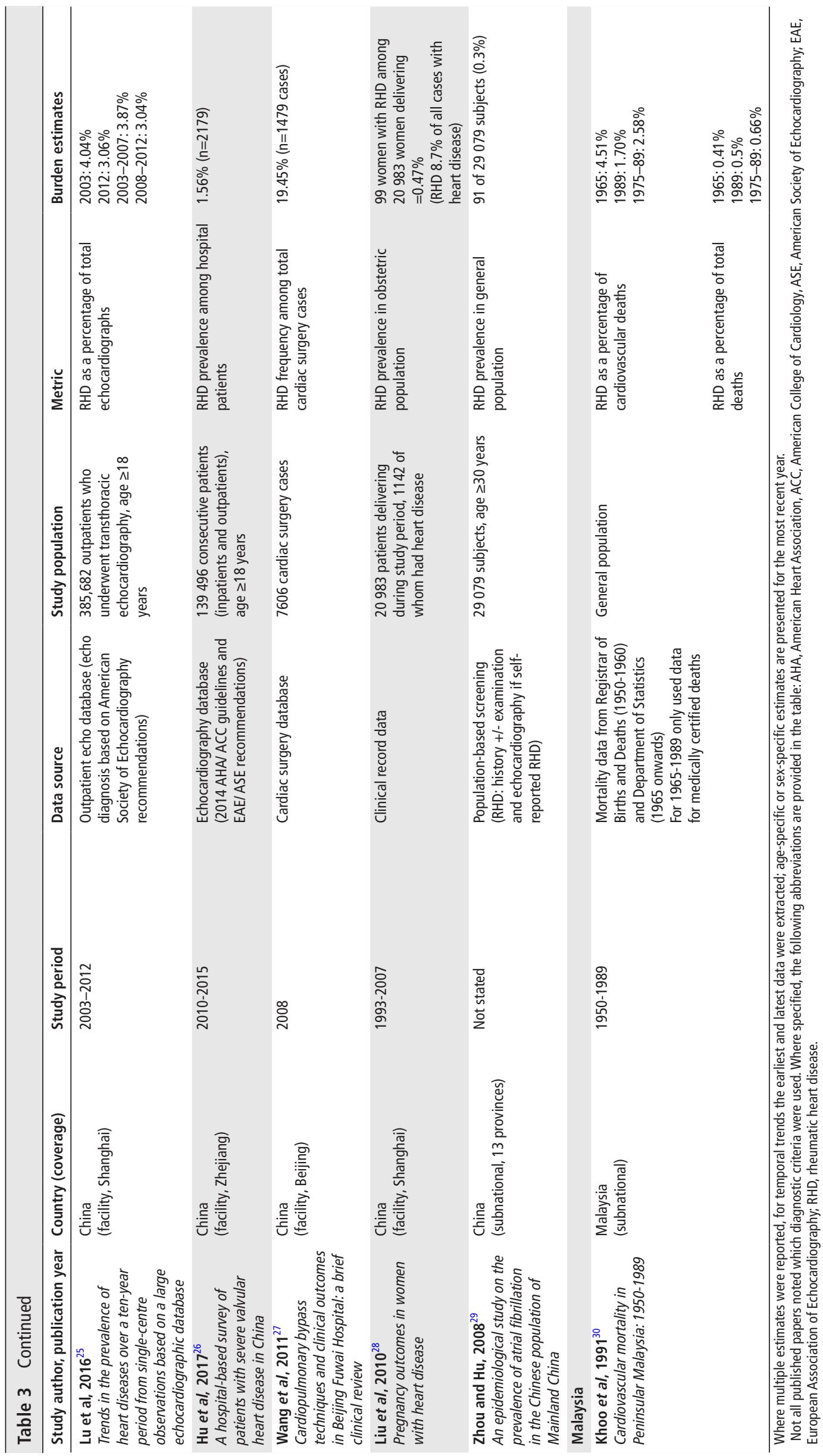


Table 4 RHD burden estimates in countries with medium 2015 human development indices, 1980-2017

\begin{tabular}{|c|c|c|c|c|c|c|}
\hline $\begin{array}{l}\text { Study author, } \\
\text { publication year }\end{array}$ & Country (coverage) & Study period & Data source & Study population & Metric & Burden estimates \\
\hline \multicolumn{7}{|l|}{ Cambodia } \\
\hline $\begin{array}{l}\text { Marijon et al, } 2007^{31} \\
\text { Prevalence of } \\
\text { rheumatic heart } \\
\text { disease detected by } \\
\text { echocardiographic } \\
\text { screening }\end{array}$ & $\begin{array}{l}\text { Cambodia } \\
\text { (Subnational - Phnom } \\
\text { Penh) }\end{array}$ & $2001-2002$ & $\begin{array}{l}\text { School screening } \\
\text { data (clinical and } \\
\text { echocardiographic } \\
\text { examination, echo } \\
\text { criteria well described } \\
\text { in paper) }\end{array}$ & $\begin{array}{l}3677 \text { school children, } \\
\text { aged 6-17 years }\end{array}$ & $\begin{array}{l}\text { RHD prevalence in } \\
\text { school children }\end{array}$ & $\begin{array}{l}\text { Clinical evidence of } \\
\text { RHD confirmed by } \\
\text { echo: } 2.2 \text { per } 1000 \\
(95 \% \mathrm{Cl} 0.7-3.7) \text {. } \\
\text { RHD prevalence on } \\
\text { echo } 21.5 \text { per } 1000 \\
(95 \% \mathrm{Cl} 16.8-26.2) \text {; } \\
\text { clinically silent RHD } \\
\text { prevalence } 19.3 \text { per } \\
1000\end{array}$ \\
\hline $\begin{array}{l}\text { Mirabel et al, } 2017^{32} \\
\text { Cardiac surgery in } \\
\text { low-income settings: } \\
10 \text { years of experience } \\
\text { from two countries }\end{array}$ & $\begin{array}{l}\text { Cambodia } \\
\text { (facility) }\end{array}$ & $2001-2011$ & Clinical data & $\begin{array}{l}1332 \text { consecutive } \\
\text { patients who } \\
\text { underwent open heart } \\
\text { surgery locally }\end{array}$ & $\begin{array}{l}\text { RHD as a percentage } \\
\text { of total cardiac surgery } \\
\text { cases }\end{array}$ & $\begin{array}{l}\text { Percentage of cardiac } \\
\text { surgeries with RHD as } \\
\text { the underlying cause: } \\
2001-2011: 36.79 \% \\
\text { (490 surgeries) } \\
2001-2006: 43 \% \\
2007-2011: 29 \%\end{array}$ \\
\hline
\end{tabular}

\section{Philippines}

Tuomihlehto

et al, $1984^{33}$

Mortality data (ICD-7 A79 and A80, ICD-8

cardiovascular diseases mortality in the

Philippines
Philippines
(national)

$\mathrm{A} 80$ and $\mathrm{A} 81$ )
General population

ARF/RHD mortality rates
The limited trend data available indicate that RHD as a proportion of total cardiovascular deaths generally decreased over time in countries across development levels, including in Malaysia ${ }^{30}$ and Japan. ${ }^{16}$ In Taiwan, age-adjusted RHD mortality rates decreased between the 1970 s and $1980 \mathrm{~s}^{35}$, and ARF/RHD mortality rates per million population also decreased between the $1950 \mathrm{~s}$ and $1980 \mathrm{~s}^{37}$. In the Philippines the crude annual death rate remained relatively unchanged in 1964-1976, although the absolute number of RHD deaths increased by more than $50 \%{ }^{33}$; in Singapore RHD mortality increased from 3.6 to 4.4 per 100000 between 1966 and $1977 .{ }^{17}$ RHD was the cause of an estimated $2.4 \%$ of heart disease deaths and $0.4 \%$ of total deaths in Japan during 1950-2008 collectively. ${ }^{15}$
Where available, contemporary RHD mortality estimates in very high development countries indicate a relatively low burden: 1.2 per 100000 population in Hong Kong in 2014, ${ }^{40}$ 1.8 per 100000 population in Japan in $2014,{ }^{41} 1.4 \%$ of total cardiovascular deaths in Brunei in $2016^{38}$ and combined ARF/ RHD mortality of less than 1 per 100000 population in Korea in $2012 .^{11}$

Among high development settings, RHD mortality rates were not found for China. In Mongolia in 2012 there were $51 \mathrm{ARF} / \mathrm{RHD}$ deaths among 16923 total deaths registered, ${ }^{42}$ equating to $3.0 \mathrm{ARF} / \mathrm{RHD}$ deaths per 1000 . The most recent data from Malaysia were for 1989, when RHD comprised $1.7 \%$ of cardiovascular deaths and $0.5 \%$ of total deaths. ${ }^{30}$ 
Table 5 RHD burden estimates in countries and areas with 2015 human development indices unspecified, 1980-2017

\begin{tabular}{|c|c|c|c|c|c|c|}
\hline $\begin{array}{l}\text { Study author, } \\
\text { publication year }\end{array}$ & Country (coverage) & Study period & Data source & Study population & Metric & Burden estimates \\
\hline \multicolumn{7}{|l|}{ Taiwan } \\
\hline \multirow{2}{*}{$\begin{array}{l}\text { Tsai and Wen, } 1989^{35} \\
\text { Mortality trends in } \\
\text { a rapidly developing } \\
\text { economy in Taiwan. } \\
\text { Part 1: Comparison } \\
\text { with the USA and } \\
\text { Japan 1976-1983 }\end{array}$} & $\begin{array}{l}\text { Taiwan } \\
\text { (national) }\end{array}$ & 1976-1983 & $\begin{array}{l}\text { Vital statistics data } \\
\text { (ICD-9 codes 393-398) }\end{array}$ & General population & $\begin{array}{l}\text { RHD as a proportion of } \\
\text { total deaths }\end{array}$ & $\begin{array}{l}\text { 1983: } \\
\text { Males } 244 \text { of } 54563 \\
\text { total deaths }(0.45 \%) \\
\text { Females } 258 \text { of } 35268 \\
\text { total deaths }(0.73 \%)\end{array}$ \\
\hline & & & & & $\begin{array}{l}\text { RHD age-adjusted } \\
\text { mortality rate }\end{array}$ & $\begin{array}{l}\% \text { change in age- } \\
\text { adjusted mortality } \\
\text { rate for RHD between } \\
\text { 1976-1983: } \\
\text { Males } 28.9 \% \text { decrease } \\
\text { Females } 25.2 \% \\
\text { decrease }\end{array}$ \\
\hline $\begin{array}{l}\text { Lue et al, } 1988^{36} \\
\text { Establishment of } \\
\text { a rheumatic heart } \\
\text { disease registry } \\
\text { in Taipei: an early } \\
\text { appraisal }\end{array}$ & $\begin{array}{l}\text { Taiwan } \\
\text { (subnational, Taipei) }\end{array}$ & 1985 & School screening study & $\begin{array}{l}462373 \text { school } \\
\text { children aged 6-18 } \\
\text { years administered } \\
\text { questionnaire. } \\
380886 \text { responses: } \\
4967 \text { suspected } \\
\text { as having RF/RHD. } \\
3716 \text { examined +/- } \\
\text { echocardiography, } 121 \\
\text { of whom found to have } \\
\text { RHD } \\
371265 \text { with no } \\
\text { symptoms reported on } \\
\text { questionnaire; } 4654 \\
\text { of whom randomly } \\
\text { sampled for exam, } 1 \\
\text { found with RHD }\end{array}$ & $\begin{array}{l}\text { RHD prevalence among } \\
\text { school children }\end{array}$ & $\begin{array}{l}\text { Adjusted prevalence } \\
\text { rate } 0.62 \text { per } 1000 \text { in } \\
1985 \\
\text { significant decline from } \\
1970 \text { ( } 1.4 \text { per } 1000 \\
\text { among } 6-13 \text { year-olds) }\end{array}$ \\
\hline \multirow{3}{*}{$\begin{array}{l}\text { Lue et al, } 1983^{37} \\
\text { Clinical and } \\
\text { epidemiological } \\
\text { features of rheumatic } \\
\text { fever and rheumatic } \\
\text { heart disease in Taiwan } \\
\text { and the Far East }\end{array}$} & $\begin{array}{l}\text { Taiwan } \\
\text { (facility) }\end{array}$ & 1946-1981 & Admissions data & Paediatric admissions & $\begin{array}{l}\text { RF/RHD frequency } \\
\text { among paediatric } \\
\text { admissions }\end{array}$ & $\begin{array}{l}\text { RF/RHD cases per } 1000 \\
\text { paediatric admissions: } \\
\text { 1946: } 5 \\
\text { 1975: } 25.6 \\
\text { 1981: 15 }\end{array}$ \\
\hline & (national) & 1956-1981 & Mortality data & General population & RF/RHD mortality rates & $\begin{array}{l}\text { 1956: } 175 \text { deaths per } \\
\text { million population } \\
\text { 1981: } 45 \text { deaths per } \\
\text { million population }\end{array}$ \\
\hline & (subnational) & $1970-71$ & Population survey & $\begin{array}{l}9425 \text { randomised } \\
\text { urban Taipei } \\
\text { population, all ages }\end{array}$ & $\begin{array}{l}\text { RHD prevalence in } \\
\text { general population }\end{array}$ & $\begin{array}{l}2.6 \text { per } 1000 \\
\text { Males } 2.0 \text { per } 1000 \\
\text { Females } 2.8 \text { per } 1000\end{array}$ \\
\hline
\end{tabular}

From medium development settings, data were only available for the Philippines, where RHD mortality was 1.7 per 100000 population among all ages in $2013 .{ }^{43}$

\section{DISCUSSION}

The WPR outside Oceania is developmentally and demographically diverse, and it follows that there is marked variation in RHD epidemiology and data availability within and between countries. Findings of this review suggest that RHD prevalence and mortality have fallen in association with economic development, particularly in very high HDI countries. In several countries that have undergone recent economic development, RHD persists particularly among older populations, a legacy of high burden in the young before socioeconomic progress. In poorer WPR countries there is a persistent RHD burden, including in young populations. This review has also highlighted considerable data gaps, particularly pronounced in less developed countries such as Laos and Vietnam. Subnational data gaps also exist in some higher HDI settings that still have substantial populations living in poverty, whose RHD burden may therefore be masked. These findings have important implications for health policy and planning nationally, regionally and globally, and reinforce that urgent and concerted efforts are required to fill the data gaps and address this avoidable disease that still exists across the region.

Consistent with known patterns of RHD distribution in different age groups by levels of economic development, in some countries with very high current HDI, RHD burden is high among older populations. For example, in South Korea crude RHD prevalence for 2008 was estimated at 220 per 100000 , with highest prevalence rates being among people aged over 60 years (791 per 100000 ), and total costs being US\$67.25 million ${ }^{9}$. Besides economic repercussions, high disease burden in older populations also has marked implications for health service planning and delivery, particularly in the context of ageing populations. A high RHD burden may generate demand on health 
Table 6 National health agency RHD burden estimates, by country and year

\begin{tabular}{|c|c|c|c|}
\hline Country & Metric & Burden estimates & Year* \\
\hline \multicolumn{4}{|c|}{ Very high HDI countries } \\
\hline Brunei & ARF/RHD as a percentage of total cardiovascular deaths & 6 ARF/RHD deaths of 421 total cardiovascular deaths $=1.4 \%$ & $2016^{38}$ \\
\hline \multirow[t]{2}{*}{ Hong Kong } & $\begin{array}{l}\text { RHD mortality rate per } 100,000 \text { population (number of RHD } \\
\text { deaths) }\end{array}$ & $\begin{array}{l}\text { Male: } 0.9 \text { per } 100,000 \text { ( } 29 \text { deaths) } \\
\text { Female: } 1.5 \text { per } 100,000 \text { ( } 59 \text { deaths) } \\
\text { Total: } 1.2 \text { per } 100,000 \text { ( } 88 \text { deaths) }\end{array}$ & $2014^{3940}$ \\
\hline & $\begin{array}{l}\text { RHD as a percentage of total heart disease In-patient Discharges } \\
\text { and Deaths in Hospital }\end{array}$ & $\begin{array}{l}1736 \text { of } 79896 \text { total heart disease inpatient discharges and } \\
\text { deaths in hospital }=2.2 \%\end{array}$ & \\
\hline Japan & $\begin{array}{l}\text { RHD mortality rate per } 100000 \text { population (number of RHD } \\
\text { deaths) }\end{array}$ & $\begin{array}{l}\text { Male: } 1.2 \text { per } 100000 \text { ( } 720 \text { deaths) } \\
\text { Female: } 2.5 \text { per } 100000 \text { ( } 1588 \text { deaths) } \\
\text { Total: } 1.8 \text { per } 100000 \text { ( } 2308 \text { deaths) }\end{array}$ & $2014^{41}$ \\
\hline
\end{tabular}

\section{Singapore}

South Korea

High HDI countries

China

Malaysia

$\begin{array}{ll}\text { Mongolia } & \text { ARF/RHD number of new cases } \\ & \text { Total population }\end{array}$

Total number of new cases: 24,116

2867744 people

$24116 / 2867744=8.4$ per 1000

ARF/RHD as a proportion of total deaths

51 ARF/RHD deaths among 16923 total deaths registered $=3.0$ per 1000 deaths

\begin{tabular}{|c|c|c|c|}
\hline \multicolumn{4}{|c|}{ Medium HDI countries } \\
\hline \multicolumn{4}{|l|}{ Cambodia } \\
\hline \multicolumn{4}{|l|}{ Laos } \\
\hline Philippines & RHD mortality rate per 100000 population (number of deaths) & $\begin{array}{l}1.7 \text { per } 100000 \text { population (1705 deaths - } 672 \text { male, } 1033 \\
\text { female) }\end{array}$ & $2013^{43}$ \\
\hline \multicolumn{4}{|l|}{ Vietnam } \\
\hline \multicolumn{4}{|c|}{ HDI not specified } \\
\hline \multicolumn{4}{|l|}{ Taiwan } \\
\hline Macao & & & \\
\hline
\end{tabular}

${ }^{*}$ Most recently available year.

ARF, acute rheumatic fever; HDI, Human Development Index; RHD, rheumatic heart disease.

services, both for treatment of the valvular disease itself and for RHD sequelae (including endocarditis, ischaemic stroke and heart failure) and comorbidities.

The high disease burden in the young in low-resource settings is also cause for concern. Peak incidence of ARF occurs at ages 5-14 years and RHD prevalence increases with age, peaking at 25-34 years. ${ }^{44}$ The only relatively recent data from the four medium HDI countries was from Cambodia-prevalence among school children aged 6-17 years in 2001-2002 was 21.5 per 1000 , with $90 \%$ being detected only on echocardiographic screen. ${ }^{31}$ Cambodia has a young population age structure, with approximately one-third of the total population aged $0-14$ years. ${ }^{4}$ It is plausible that a similarly high burden of undetected disease exists in the other countries with similar levels of development and age structure.

In China, studies since 2000 indicate persistent burden among school children aged $5-13$ years ${ }^{21}$ and the general population aged 30 and over ${ }^{29}$ and 18-74 years. ${ }^{20}$ Available Chinese data were predominantly from large cities; many less developed provinces had data gaps. Despite China's considerable socioeconomic progress, pronounced socioeconomic inequality exists ${ }^{7}$ and RHD burden may well be higher in less developed, datapoor regions. Additionally, China's large population size means that high rates translate into considerable absolute numbers of people living with RHD-prevalence of 2 per 1000 equates to an estimated 2 million middle-aged and elderly adults. ${ }^{20}$ RHD has generally decreased as a proportion of total medical and cardiac admissions over recent decades, likely reflecting China's epidemiological transition with an associated increase in the burden of lifestyle-related conditions such as type 2 diabetes and ischaemic heart disease.

For several WPR countries, contemporary estimates of disease burden were not available in the peer-reviewed literature. In settings that now have very high HDI, this probably indicates RHD is no longer a public health priority. The prevalence study from Japan reported a progressively declining burden among school children over time, to 0.14 cases per 1000 in $1981 .^{14}$ Similarly for Hong Kong, population prevalence among university students was low and the proportion of RHD hospital admissions progressively declined over the 1960 s to 1980 s. $^{12} 13$ Although it is appropriate that resources are directed to areas of contemporary priority, there is no room for complacency, as highlighted by recent Japanese reports that between 2010 and 2015 there were 44 new cases of ARF occurring predominantly in large Japanese cities. ${ }^{45}$ In WPR and beyond, it is important that even highly developed nations remain vigilant to ARF and RHD. ${ }^{46}$

Data gaps elsewhere warrant attention because they occur particularly in settings where socioeconomic conditions would suggest that RHD burden is likely to be high. Several countries had high burden documented but no recent follow-up studies to gauge progress. In the Philippines, an early study documented a $13 \%$ increase in the ARF/RHD proportional mortality rate between 1964 and $1976,{ }^{33}$ and a preliminary report on Filipino school screening (data to June 1998) indicated an RHD prevalence of 1 per $1000 .{ }^{34}$ More contemporary estimates were not found in the published literature. However, health department reports of mortality rates of 1.7 per 100000 in $2013^{43}$ indicate 
that RHD persists. A single Malaysian study reported cardiovascular mortality between 1950 and $1989,{ }^{30}$ but no contemporary mortality statistics and no population-based estimates of RHD prevalence were located, as noted by others. ${ }^{47}$ Some developing countries had no data whatsoever. Globally, the volume of ARF/ RHD research in the published literature has declined markedly over time, in parallel with and reflecting the decreased disease burden in developed nations, but this waning interest comes at the expense of information deficits in developing settings where disease burden is likely greatest. ${ }^{48}$

In some low-resource settings poorly developed health information infrastructure means that there are little real data about the health status of populations, including RHD burden. For example, mortality data are often unavailable because of inadequately functioning civil registration and vital statistics systems and poor rates of medical certification of cause of death. ${ }^{49}$ Data gaps mean that there is a reliance on statistically modelled estimates such as the Global Burden of Disease study ${ }^{50}$ to gauge disease burden.

Modelling studies help bridge information gaps. However, there are limitations, assumptions and uncertainties inherent in any model, and a model is only as good as its data inputs. For some WPR countries, modelled estimates differ considerably from other data sources. These estimates may not be directly comparable if the primary data signals are of poor quality or insufficiently described-paucity of information about diagnostic methods, case definitions, reporting requirements and other metadata may mean that modelled metrics and indicators derived from other data are not measuring the same thing, precluding direct comparison. For mortality estimates, differences may arise due to incomplete or poor quality death data requiring statistical correction for completion. In other cases, where local data are unavailable, modelled estimates are derived using data from other settings. Models are best enhanced by improving the primary data inputs. It is imperative that there is improved collection of real world data to more accurately understand the true situation on the ground.

There are several potential limitations to this work. Relevant papers may have been excluded or missed. Additionally, as this review only captured English-language peer-reviewed publications and government reports, burden estimates reported in other languages or sources were not considered. There are inherent difficulties in measuring RHD burden, including screening methodology and variation in the quality and completeness of civil registration systems and cause of death statistics across the region. Differences in study methodology, data sources, study periods, geographical coverage and study populations preclude direct comparison. In particular, the change from auscultation to echocardiographic screening (including World Heart Federation criteria for echo screening) is associated with significant changes in sensitivity. ${ }^{3151}$ The metrics complied in this review encompass a range of indicators, methodologies and study population groups, and the measures reported differ both within some countries and between countries. This makes it difficult to accurately gauge progress over time, but this issue reflects the difficulties arising from not having standardised, consistent and serial measurement. Finally, settings with poor information infrastructure are also the ones most likely to have a considerable disease burden; hence, official statistics may not completely capture all cases/deaths.

Nonetheless, this paper tells the story of successes achieved in controlling RHD in some parts, where falling prevalence is followed by declining representation in biomedical literature. It also highlights information gaps and evidence of disease hot spots throughout the WPR beyond Oceania, indicating a need for active and ongoing disease control initiatives, and a focused regional effort to address this issue.

Elsewhere, high disease burden has precipitated strong calls to address this avoidable disease of disadvantage, including from across Africa $^{52}$ and from the World Heart Federation, who have called for a $25 \%$ reduction in RHD mortality in those aged under 25 years by $2025 .{ }^{53}$ In the sustainable development goals era, the impetus to address poverty and the underlying social and systemic determinants of disease has never been greater. Achieving RHD control is now on the agenda at the highest levels of global health diplomacy. ${ }^{54}$ Concerted efforts across WPR are required to fill information gaps and ensure that targeted, contextually relevant actions are adopted where needed. Serial monitoring of disease burden is crucial to gauge progress and ensure that the whole region is on track to banishing RHD to the history books.

Correction notice This article has been corrected since it was published Online First. The sentence 'comprised $1.6 \%$ of all adult admissions. ${ }^{26}$ ' has been changed to read 'prevalence was $1.6 \%$ in adult patients. ${ }^{26 r}$

Acknowledgements We wish to acknowledge Scott Sims of the Telethon Kids Institute, University of Western Australia, for his graphical work in producing the maps.

Contributors MA conceived and designed the study; undertook literature search, reviews and data extraction; synthesised and interpreted results; drafted manuscript. JK undertook literature search, reviews and data extraction; synthesised and interpreted results; edited manuscript. RW conceived and designed the study, interpreted results, edited manuscript. DW conceived and designed the study, interpreted results, edited manuscript. TDJ assisted with data collection, proofread manuscript. JC conceived and designed the study, interpreted results, edited manuscript and is the study guarantor.

Funding MA, RW, DW and TDJ are supported by the Medtronic Foundation grant to RhEACH. JK is supported by a National Heart Foundation Future Leader Fellowship.

Competing interests None declared.

Provenance and peer review Not commissioned; externally peer reviewed.

Open Access This is an Open Access article distributed in accordance with the Creative Commons Attribution Non Commercial (CC BY-NC 4.0) license, which permits others to distribute, remix, adapt, build upon this work non-commercially, and license their derivative works on different terms, provided the original work is properly cited and the use is non-commercial. See: http://creativecommons.org/ licenses/by-nc/4.0/

(c) Article author(s) (or their employer(s) unless otherwise stated in the text of the article) 2017. All rights reserved. No commercial use is permitted unless otherwise expressly granted.

\section{REFERENCES}

1 Watkins DA, Johnson CO, Colquhoun SM, et al. Global, regional and national burden of rheumatic heart disease, 1990-2015. N Engl J Med 2017;377:713-22.

2 Rothenbühler M, O'Sullivan CJ, Stortecky S, et al. Active surveillance for rheumatic heart disease in endemic regions: a systematic review and metaanalysis of prevalence among children and adolescents. Lancet Glob Health 2014;2:e717-e726.

3 World Health Organization. WHO in the Western Pacific. http://www.wpro.who.int/ about/in brief/en/.

4 The World Bank 2017. World DataBank. Health Nutrition and Population Statistics http://databank.worldbank.org/data/reports.aspx?source=health-nutrition-andpopulation-statistics.

5 United Nations Development Programme 2017. Human Development Data (19902015). http://hdr.undp.org/en/data.

6 Colquhoun SM, Carapetis JR, Kado JH, et al. Rheumatic heart disease and its control in the Pacific. Expert Rev Cardiovasc Ther 2009;7:1517-24.

7 UNDP China, Development Research Center of the State Council of China 2016. China National Human Development Report 2016: Social Innovation for Inclusive Human Development. Beijing: China Publishing Group Corporation. 
8 Bae JH, Hong SJ, Park WH, et al. The frequency distribution of cardiovascular diseases in 13 hospital admitted patients in Korea. Korean Society of Circulation. J Korean Med Sci 1987;2:141-50.

9 Seo HY, Yoon SJ, Kim EJ, et al. The economic burden of rheumatic heart disease in South Korea. Rheumatol Int 2013;33:1505-10.

10 Jang SY, Ju EY, Seo SR, et al. Changes in the etiology of valvular heart disease in the rapidly aging Korean population. Int J Cardiol 2014;174:355-9.

11 Lee SW, Kim HC, Lee HS, et al. Thirty-year trends in mortality from cardiovascular diseases in Korea. Korean Circ J 2015;45:202-9.

12 Woo KS, Kong SM, Wai KH. The changing prevalence and pattern of acute rheumatic fever and rheumatic heart disease in Hong Kong--(1968-1978). Aust N Z J Med 1983;13:151-6.

13 Woo KS, Vallance-Owen J. Changing prevalence and pattern of cardiovascular diseases in Hong Kong. A perspective in the 1990s. Chin Med J 1988;101:579-86.

14 Kawakita S. Rheumatic fever and rheumatic heart disease in Japan. Jpn Circ J 1986;50:1241-5.

15 Takahashi I, Shimizu Y, Grant EJ, et al. Heart Disease Mortality in the Life Span Study, 1950-2008. Radiat Res 2017;187:319-32.

16 Takamori A, Takahashi I, Kasagi F, et al. Mortality Analysis of the Life Span Study (LSS) Cohort Taking into Account Multiple Causes of Death Indicated in Death Certificates. Radiat Res 2017;187:20-31.

17 Sheares JH, Tan KT, Wu DC, et al. Surgical management of rheumatic heart disease in Singapore. Ann Acad Med Singapore 1981;10:101-9.

18 Loh FH, Arulkumaran S, Montan S, et al. Maternal mortality: evolving trends. Asia Oceania J Obstet Gynaecol 1994;20:301-4.

19 Xuan XY, Rao XX, He HM, et al. Epidemiology and community control of rheumatic heart disease in Panyu county. Chin Med J 1980;93:800-2.

20 Zhimin W, Yubao Z, Lei S, et al. Prevalence of chronic rheumatic heart disease in Chinese adults. Int J Cardiol 2006;107:356-9.

21 Kang G, Xiao J, Wang Y, et al. Prevalence and clinical significance of cardiac murmurs in schoolchildren. Arch Dis Child 2015;100:1028-31.

22 Chen $\mathrm{H}$, Fan W, Jin X, et al. Changing pattern of heart diseases in Shanghai from the 1950s to 1980s. Chin Med J 1999;112:14-17.

23 Cheng TO. How much of the recent decline in rheumatic heart disease in China can be explained by changes in cardiovascular risk factors? Int I Cardiol 2009;132:300-2.

24 Liu FZ, Xue YM, Liao HT, et al. Five-year epidemiological survey of valvular heart disease: changes in morbidity, etiological spectrum and management in a cardiovascular center of Southern China. J Thorac Dis 2014;6:1724-30.

25 Lu H, Pan WZ, Wan Q, et al. Trends in the prevalence of heart diseases over a ten-year period from single-center observations based on a large echocardiographic database. J Zhejiang Univ Sci B 2016:17:54-9.

26 Hu P, Liu XB, Liang J, et al. A hospital-based survey of patients with severe valvular heart disease in China. Int J Cardiol 2017;231:244-7.

27 Wang S, Lv S, Guan Y, et al. Cardiopulmonary bypass techniques and clinical outcomes in Beijing Fuwai Hospital: a brief clinical review. Asaio J 2011;57:414-20.

28 Liu H, Xu JW, Zhao XD, et al. Pregnancy outcomes in women with heart disease. Chin Med J 2010;123:2324-30.

29 Zhou Z, Hu D. An epidemiological study on the prevalence of atrial fibrillation in the Chinese population of mainland China. J Epidemiol 2008;18:209-16.

30 Khoo KL, Tan H, Khoo TH. Cardiovascular mortality in Peninsular Malaysia: 19501989. Med J Malaysia 1991;46:7-20.

31 Marijon E, Ou P, Celermajer DS, et al. Prevalence of rheumatic heart disease detected by echocardiographic screening. N Eng/ J Med 2007;357:470-6.

32 Mirabel M, Lachaud M, Offredo L, et al. Cardiac surgery in low-income settings: 10 years of experience from two countries. Arch Cardiovasc Dis 2017;110:82-90.

33 Tuomilehto J, Morelos S, Yason J, et al. Trends in cardiovascular diseases mortality in the Philippines. Int J Epidemiol 1984;13:168-76.
34 Imperial ES, Cabrera E, Reyes-Asido LD, et al. The Albay Province rheumatic fever/ rheumatic heart disease prevention and control program - a preliminary report. PhilippJ Cardio 1998;2:136-42.

35 Tsai SP, Wen CP. Mortality trends in a rapidly developing economy in Taiwan. Part I: Comparison with the USA and Japan 1976-1983. Asia Pac J Public Health 1989;3:41-50.

36 Lue HC, Wu MH, Hwang BT, et al. Establishment of a rheumatic heart disease registry in Taipei: an early appraisal. N Z Med J 1988;101:410-1.

37 Lue HC, Tseng WP, Lin GJ, et al. Clinical and epidemiological features of rheumatic fever and rheumatic heart disease in Taiwan and the Far East. Indian Heart $J$ 1983;35:139-46.

38 Ministry of Health Brunei Darussalam. Health Information Booklet 2016 (21st Edition Revision 1) Brunei Darussalam. 2016 http://www.moh.gov.bn/ SiteCollectionDocuments/Health\%20Indicator\%20Booklet/HIB_2016.pdf.

39 The Government of the Hong Kong Special Administrative Region. Non-Communicable Diseases - Highlights Report. Hong Kong: Healthy Hong Kong, Department of Health, 2014 Number of Inpatient Discharges and Deaths in Hospital by Heart Disease Group 2014. http://www.healthyhk.gov.hk/phisweb/en/health_info/non_comm_dis/comm_ ncd/report.html.

40 The Government of the Hong Kong Special Administrative Region. Non-Communicable Diseases - Highlights Report. Hong Kong: Healthy Hong Kong, Department of Health, 2014. Number of Deaths and Death Rate by Heart Disease Group by Sex, 2005 - 14. http://www.healthyhk.gov.hk/phisweb/en/health_info/non_comm_dis/comm_ncd/ report.html.

41 Ministry of Health Labour and Welfare. Handbook of Health and Welfare Statistics. 2015 http://www.mhlw.go.jp/english/database/db-hh/1-2.html.

42 Center for Health Development. Health Indicators. 2012 http://www.chd.mohs.mn/ images/pdf/sma/2013/eruul_mendiin_uzuulelt_2013_eng3(1).pdf.

43 Epidemiology Bureau. The 2013 Philippine Health Statistics. Republic of the Philippines: Department of Health, 2013. http://www.doh.gov.ph/sites/default/files/ publications/2013PHScompressed_0.pdf.

44 Carapetis JR, McDonald M, Wilson NJ. Acute rheumatic fever. The Lancet 2005;366:155-68.

45 Sato S, Uejima Y, Suganuma E, et al. A retrospective study: Acute rheumatic fever and post-streptococcal reactive arthritis in Japan. Allergol Int 2017. In Press.

46 Roth GA, Dwyer-Lindgren L, Bertozzi-Villa A, et al. Trends and Patterns of Geographic Variation in Cardiovascular Mortality Among US Counties, 1980-2014. JAMA 2017:317:1976-92.

47 Hung LC, Nadia R. A Review of Acute Rheumatic Fever and Rheumatic Heart Disease Research in Malaysia. Med J Malaysia 2016;71:79-86.

48 Carapetis JR. Rheumatic heart disease in developing countries. N Eng/ J Med 2007;357:439-41.

49 World Health Organization. WHO Mortality Database. 2017 http://www.who.int/ healthinfo/mortality_data/en/.

50 Institute for Health Metrics and Evaluation. Global Health Data Exchange. Seattle, 2016

51 Reményi B, Wilson N, Steer A, et al. World Heart Federation criteria for echocardiographic diagnosis of rheumatic heart disease--an evidence-based guideline. Nat Rev Cardiol 2012;9:297-309.

52 Watkins D, Zuhlke L, Engel M, et al. Seven key actions to eradicate rheumatic heart disease in Africa: the Addis Ababa communiqué. Cardiovasc J Afr 2016;27:184-47

53 Remenyi B, Carapetis J, Wyber R, et al. Position statement of the World Heart Federation on the prevention and control of rheumatic heart disease. Nat Rev Cardiol 2013;10:284-92.

54 World Health Organization. Rheumatic fever and rheumatic heart disease. Agenda Item 6.2. EB 141.R1. 2017. http://apps.who.int/gb/ebwha/pdf_files/EB141/B141_R1en.pdf. 